\title{
The Role of ICT Solutions In the Intelligent Enterprise Business Activity
}

\author{
Monika Łobaziewicz \\ University College of Enterprise \\ and Administration in Lublin, \\ Poland \\ e-mail:ml@un.pl
}

\begin{abstract}
During the last years the number of innovative ICT systems, applications and tools has been growing still to support intelligent business performance. However, advanced ICT solutions are only means to the end of better process performance, not a substitute for it. Intelligent enterprises running their activity in increasingly more dynamic, complex and uncertain environment. The aim of paper is the discussion about the wide spectrum of ICT solutions used by the intelligent enterprise and their meaning in the management of intelligent organization. This is the first approach in this case that the author is going to continue in the advanced research.
\end{abstract}

\section{INTRODUCTION}

There are many definitions of an intelligent enterprise. Undoubtedly, it has a high abilities to learn from experience, adapt to new situations, understand and handle abstract concepts, and use knowledge to manipulate the business environment. Problem solving, comprehending complex ideas, learning quickly, and learning from experience are crucial for the intelligent enterprise. Companies today are looking to boost operational productivity and performance while addressing the full range of information requirements throughout the extended enterprise. In this case, the intelligence in the enterprise management is more than just delivering reports from a data warehouse. It's about providing large numbers of people - executives, analysts, customers, partners, and everyone else - secure and simple access to the right information so they can satisfy their unique reporting or analysis requirements, then share that information accordingly.

The intelligent enterprise provides information for serviceoriented purposes and for optimizing operational systems.

The enterprise can be intelligent in two ways:

$\checkmark$ It can behave intelligently or/ and can „utilize” intelligence;

$\checkmark$ For the enterprise to be intelligent, it needs to maximize the extend and utility of its intellectual capital;

$\checkmark$ The intelligent enterprise is an organization which acts effectively in the present and is capable of dealing effectively with the challenges of the future. It meets its objectives both of the enterprise itself and those of its stakeholders and makes trade - offs between them.

Because, the role of ICT in business management is crucial and modern enterprises run their activity using advanced IT systems, applications, tools - the question concerning the differences between intelligent and traditional enterprise appears.

The aim of paper is the discussion about the wide spectrum of ICT solutions used in the intelligent enterprise and their meaning in the management of intelligent organization. This is the first approach in this case that the author is going to continue in the advanced research.

\section{II.THE INTELLIGENT ENTERPRISE}

Nowadays, the concept of an intelligent enterprise has its source particularly in the following ideas: an organisation based on knowledge and information management, a learning organization, an organisation based on the intellectual capital. On the other hand, from the ICT point of view, the intelligent enterprise is correlated with following terms: business intelligence, artificial intelligence, enterprise intelligence systems. The results of a literature surveys conduct that a discussion about the intelligent organisation has been started in 90 . of the 20 'th century. The concept of the "intelligent enterprise" was first articulated by J. B. Quinn as follows "the self-sufficient enterprise is becoming anachronistic. Each organization is part of a matrix of merging and evolving ideas and opportunities. Leading companies focus less on positioning and more on patterns of people and institutions they work with - or against" [1] and now it has a special meaning because of the use of advanced tools based on ICT.

Ming \& Feng [2], Hopkins Lavalle, Balboni [3], Kruschwitz \& Shockley [4], Dayani [5], Quinn [6], Stubbs [7], Tan \& Cao $[8,9]$ note that the knowledge management, wireless networking technologies, mobile devices has prompted many modern enterprises to look for management information systems to remotely monitor and control of their company operations in order to increase their flexibility and competitiveness in the market. In other words, the intelligent enterprise operates with knowledge- 
based technologies, especially on-line systems for remote work and activities improving the effectiveness of business processes and has important role in creating competitive advantage.

Szczerbicki [10] notices that a modern intelligent enterprise is able to convert intellectual resources using ICT solutions to the end product with a high level of added value.

One should be pointed that now intelligent enterprises use in their business a hybrid approach rather than using a single intelligent system or application to do activities and to make decisions. Modern IT environment includes various interfaces and components completely Web-based and uses XML extensively which can work like shared platform to be accessed by multiple users and decision makers [11]. Enterprises operate on B2B platforms with 'in built' EDI technologies that integrate ERP systems and special applications of business partners, use the workflow, CRM. All of them provide a lot of data and information in the integrated way. Thus, they act like knowledge management systems [12], [13]. Nowadays the main problem for the intelligent enterprise is not be the access to information but the ability to verify it and then to transform it into a useful operational and strategic resource.

Managing of the enterprises that function in uncertain 'information-rich' environment requires greater understanding of the role of information and in systems operation. To gain this understanding, the knowledge is required [14]. In the intelligent enterprise, employees know that ICT tools enable the knowledge sharing, not only fosters collaboration but also facilitates experience and knowledge discovery. Thannhuber emphasizes that IT systems supported by knowledge and intelligence paired together allow to adapt dynamically the enterprise to its environment, provide the framework for making optimal decisions [15]. Moreover, the intelligent enterprise applies automated analytics on data generated by systems and applications to better understand what resources are being used, how well they should be used to support the business processes. The intelligent enterprises create the high ability to measure past performance for the future purposes. ICT solutions deliver knowledge to the right people when and where it is needed, and keep in mind that timeliness is an issue. The issue is that not everybody needs all information, they need just the right information for themselves. In the intelligent enterprise, there is a situation when delivering reports from a data warehouse is an operational action. The intelligence of this organization is about providing large numbers of people - executives, analysts, customers, partners, and everyone else - secure and simple access to the right information so they can satisfy their unique reporting or analysis requirements, then share that information accordingly to the logic of business processes.
According to Dayal [16] the intelligent enterprise is characterized by being able to adapt quickly to changes in its operating environment. It monitors not only its own business processes but its interactions with customers, partners, suppliers and collaborators, as well. The intelligent enterprise understands how the exchange of information among all business participants relates to its business objectives and it acts to control and optimize its operations to meet its business objectives. In this enterprise decisions are made quickly and accurately to modify business processes on the fly, dynamically allocate resources, or change business partners (e.g., suppliers, service providers) and partnerships (e.g., establish new service level agreements).

\section{BUSINESS MODELS OF THE INTELLIGENT ENTERPRISE}

The results of literature surveys conduct that there are very little discussion about business models of the intelligent enterprise. Most of the conceptions are related to business intelligence (BI) or knowledge management(KM) models. There are a few concepts presented as white papers or presentations exposed at IT conferences.

Professor Larry Lucardie from Knowledge Value Institute defines the intelligent enterprise as lean, agile and learning, which a business model is based on the knowledge value (Fig. 1).

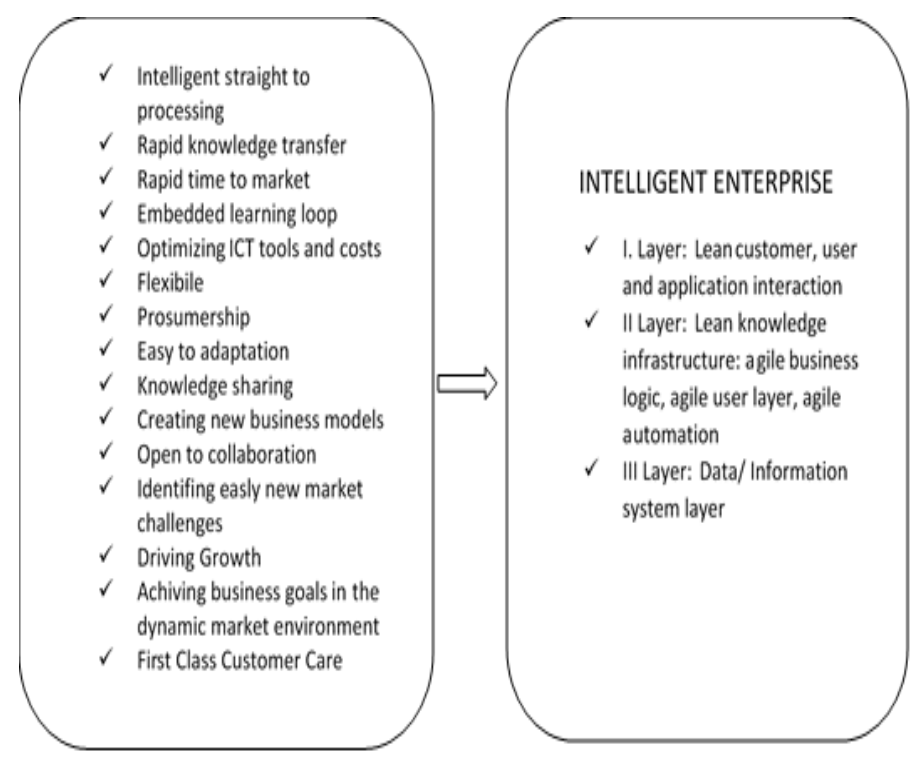

Fig. 1 Intelligent enterprise optimizing the knowledge driven organisation

Andrew Coleman from IBM notices that the business model of intelligent enterprise is based on prediction. The intelligent organisation is able to compare what is happening right now with past experience to predict the future so that it can anticipate the changes needed to proactively optimize the business. Therefore, the intelligent enterprise is a market game changer (Fig. 2). 


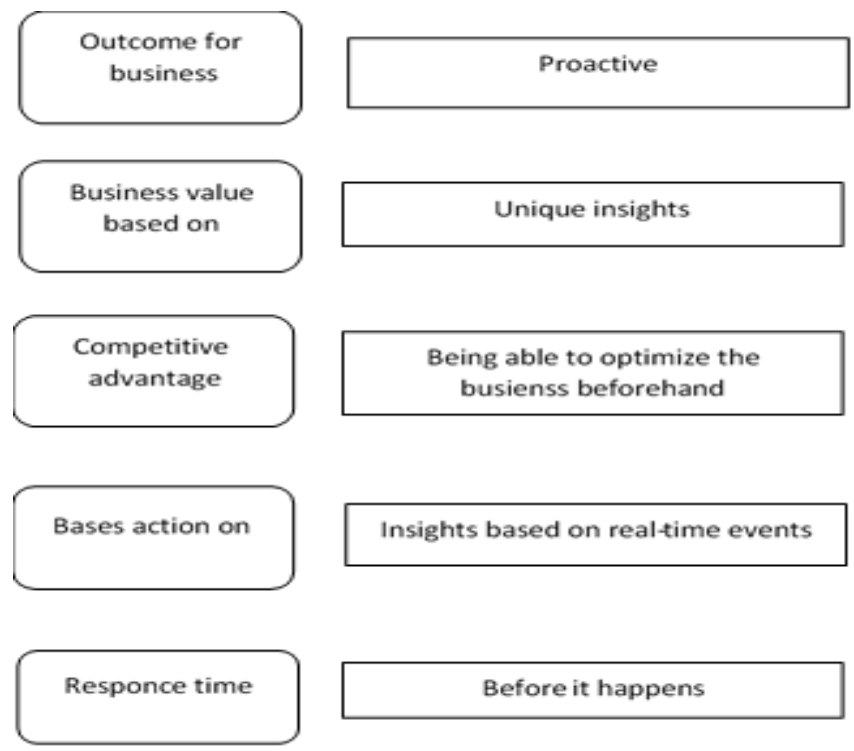

Fig. 2 Predictive intelligent enterprise model

The research conducted by IBM in a group of 225 business leaders worldwide, show that enterprises are operating with bigger blind spots and that they are making important decisions without access to the right information. They recognize that new analytics, coupled with advanced business process management capabilities, signal a major opportunity to close gaps and create new business advantage. Those who have the vision to apply new approaches are building intelligent enterprises and will be ready to outperform their peers [17]. IBM have pointed the essential characteristics that describe an enterprise ready to exploit advanced analytics and optimized performance (Fig. 3).

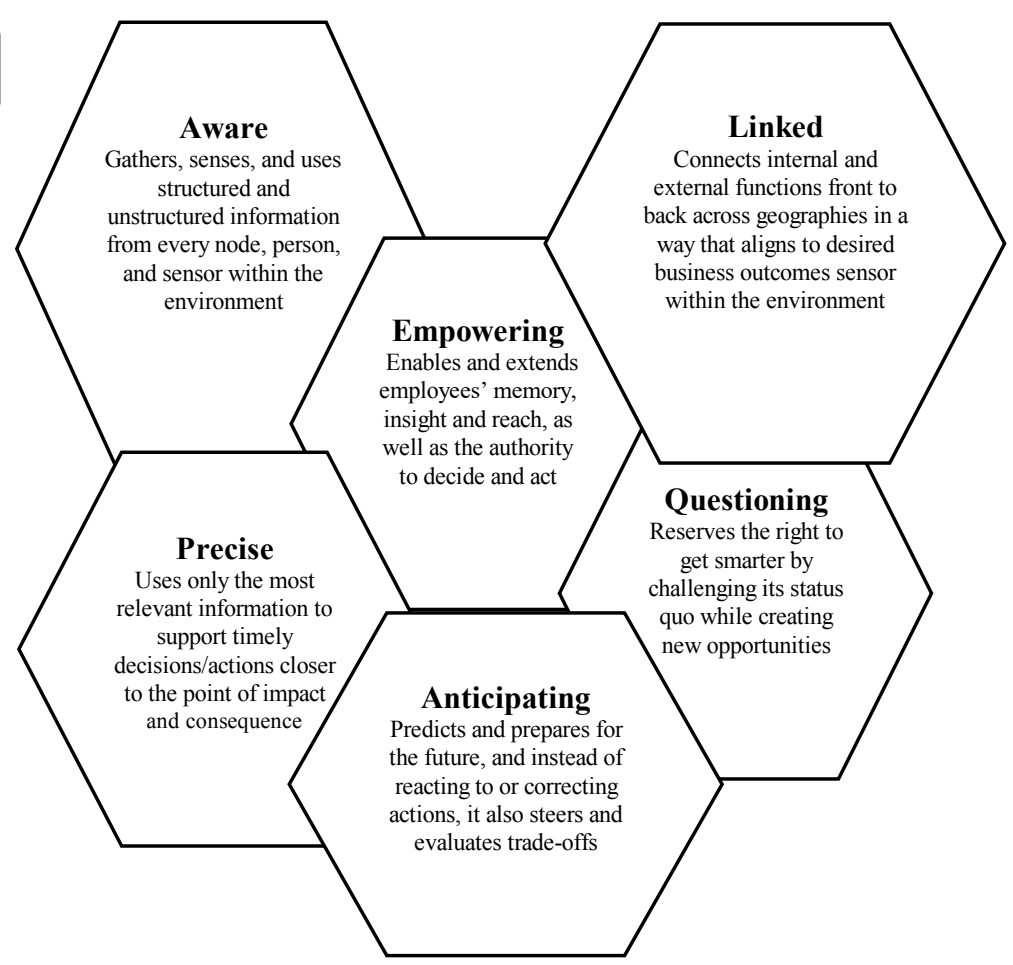

Fig. 3 Characteristics of the intelligent enterprise in IBM conception

Intelligent enterprises operate in increasingly complex IT systems what is the result of business processes complexity. Autonomous subsystems are still be interrelated and embedded in larger systems. Intelligent enterprises opposite to traditional organizations are able to integrate their strategy and the knowledge management with IT systems, applications and tools (Fig. 4).

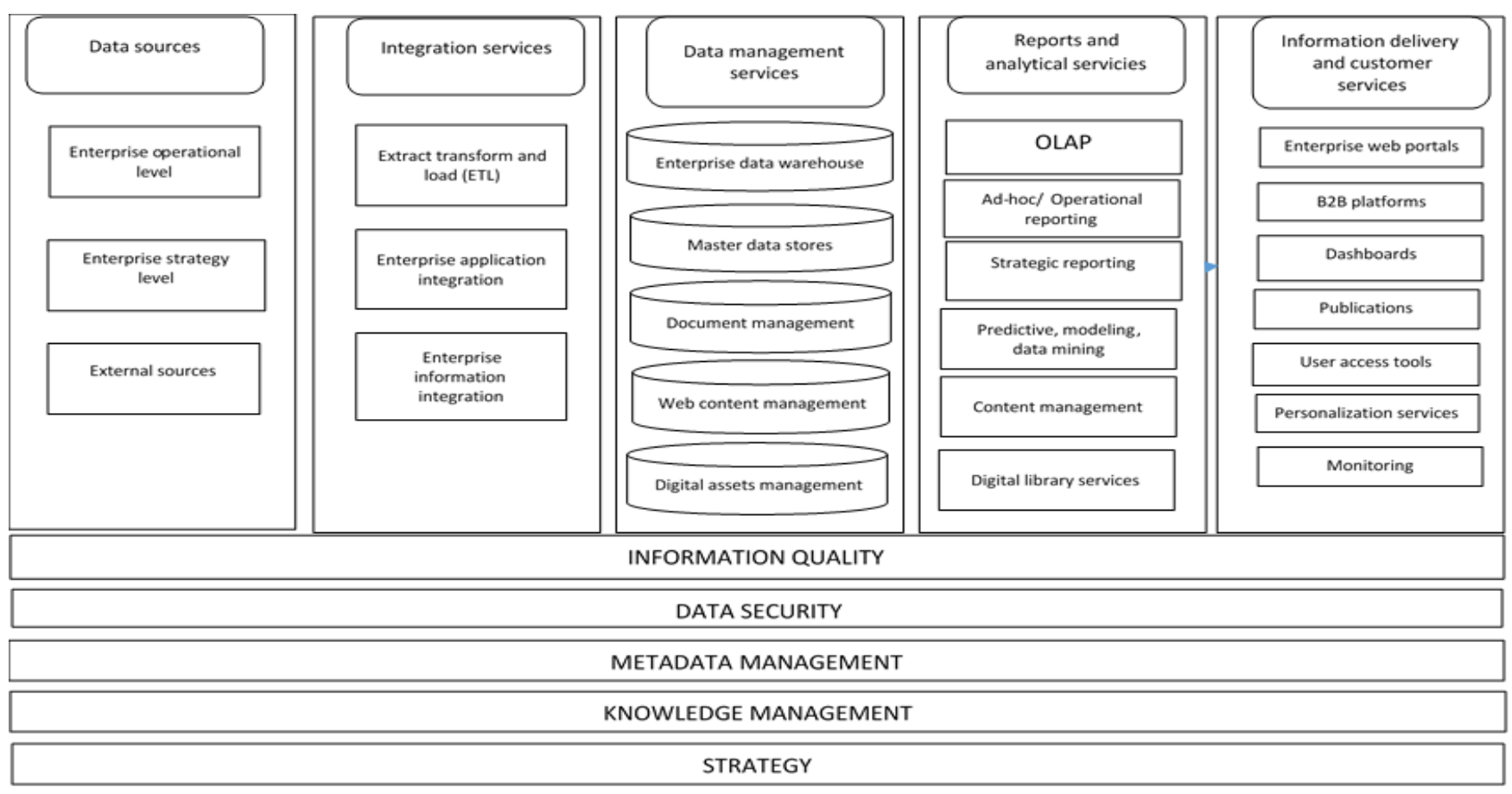

Fig. 4 Integrated intelligent enterprise model 
Building the business model of the intelligent enterprise provides for a strategy and technology infrastructure that ensures that accurate and timely information is effectively incorporated into the decision making process so that the organizations can exploit this information through process, knowledge and visualization based technologies to manage their business effectively.

\section{THE RESEARCH OF INTELLIGENT ENTERPRISE}

The study show that there is a lack of advanced surveys devoted to the intelligent enterprises.

Up to date, in Poland the only research concerning intelligent enterprises was carried out by Polish Agency for Enterprise Development (PARP) in 2010 on a group of 300 small and medium-sized enterprises (SMEs). One of the purpose of the research was finding an answer to a question what are the characteristics of the intelligent enterprise in Poland and whether they use ICT solutions more effectively than other organisations.

In the research carried out by PARP it was assumed that an intelligent organisation has following features:

- it has a long term strategy of development to achieve goals;

- it has an advanced human resources management (HRM) policy;

- it has a company website and intra network as well as it uses specialised ICT business management tools;

- it uses the knowledge management.

Surveys have shown that $26.5 \%$ of SMEs had a long term strategy, $31.6 \%$ had the HRM policy, $47 \%$ used developed ICT tools and 38\% used the knowledge management. In contrast, $63 \%$ of big companies had both the strategy and the personnel management policy well developed. Therefore, the bigger organisations meet the criteria of intelligent organisation to a larger extent than SMEs.

In Poland, intelligent organizations do not have a clear innovative profile yet established. Now, when the Operational Programme Intelligent Development 20142020 started, it is known that a type of innovation is not a factor differentiating companies in terms of their willingness to implement solutions typical for intelligent organizations. More often are process innovations (28\%), organizational innovations $(24 \%)$ and product innovations (21\%). The tendency to introduce the solutions adequate for intelligent organizations to the business practice increases with the size of company turnover. From the business sector point of view, intelligent organisations have the biggest share among industrial companies (14\%), as well as trade and service companies.

The research indicate then a stronger focus on technological development among intelligent organizations, their better adaptation to the challenges of the knowledge based economy, the speed of access to knowledge and the possibility of its use are key competitive factors.

Intelligent organizations in Poland more often use ICT solutions to support management processes in comparison with other organizations. The most popular are e-workflow, databases and data warehouses management $(83 \%)$, as well as Intranet $(76 \%)$. The further are Customer Relationship Management (twice more often than organizations that do not meet criteria for intelligent organizations) and solutions supporting a team working, every fifth - HRM and every sixth - Business Intelligence (three times more often than other organizations).

The last problem concerning ICT solutions that support the management of intelligent organizations is their effectiveness assessment. The few critical comments were focused on low efficiency of databases and data warehouses. Very positively were evaluated Supply Chain Management (78\%) and Customer Relationship Management (70\%). As far as the effectiveness of various ICT tools by intelligent organizations is concerned, it is worth to emphasize that generally ICT tools are assessed as less effective by small businesses than by middle sized and large. This is due to the specific nature of these tools, which do not necessarily have to be effective in organizations with a low developed organizational structure and not very complicated business processes [18].

In 2010 MIT Sloan Management Review and the IBM Institute for Business Value conducted a research among nearly 3,000 executives, managers and analysts working across more than 30 industries and involved intelligent organizations of various sizes in more than 100 countries. There were also interviewed academic experts and subject matter experts from a number of industries and disciplines to understand the practical issues facing intelligent organizations [19].

As a result, there are following results:

- Intelligent enterprise is focused on the highest value uses each business opportunity, starting with questions, not data opposite to traditional organizations. It should first define the insights and questions needed to meet the big business objective and then identify data needed for targets. They can target specific subject areas, and use readily available data in the initial analytic models;

- Intelligent enterprise drives actions and delivers value. This means that new methods and tools to embed information into business processes, ICT analytics solutions, optimization, workflows and simulations are making insights more understandable and actionable;

- Intelligent enterprise develops existing capabilities adding new ones. To do this, they use sophisticated modelling and visualization tools based on ICT, but that does not mean that spreadsheets and charts should go away. On the contrary, new tools should supplement earlier ones, or continue to be used side by side, as needed; 
- Intelligent enterprise uses an information agenda to do plan for the future. Big data is getting bigger. Information is coming from interconnected supply chains today. Strategic information arrives through unstructured digital channels: social media, smart phone applications and an ever-increasing stream of emerging Internet-based gadgets. The information agenda identifies foundational information practices and tools while aligning IT and business goals through enterprise information plans and financially justified deployment road maps. This agenda helps establish necessary links between those who drive the priorities of the organization by line of business and set the strategy, and those who manage data and information. A comprehensive agenda also enables managers to keep pace with changing business goals. It provides a vision and high-level road map for information that aligns business needs to growth. [3]

Summing up, intelligent enterprises are combining the new systems and tools based on ICT with expertise in business process management. They are able to extract the precise information they need - highly relevant and contextualized - and predict the most likely outcomes of key decisions and events. They are able to shape their own futures.

\section{V.ICT DRIVERS EMPOWERING THE INTELLIGENT ENTERPRISE}

The results of theoretical study and the research conducted by PARP and MIT Sloan Management Review and the IBM Institute for Business Value became the background to develop a scientific discussion about the intelligent enterprise and the role of ICT in this organization. Taking into account the wide spectrum of ICT solutions used in the intelligent enterprise management, there are some areas to analyse.

\subsection{Mobile workforce integration}

The access to professional knowledge is critical in the intelligent enterprises and mobile connections to operating systems, applications, platforms are important, especially in the fast - paced business environment. Mobile technologies drive technical innovation to improve networks, ensure employees remain fully integrated with their company and clients wherever they are. Thus, in the intelligent organization its coherency is determined by the intelligence of its network that becomes the organization with wireless tentacles spreading from it to embrace location-aware services.

\subsection{Smart virtual workplace}

As the approaches to virtualization of IT infrastructure, networks and storage devices continue to mature, infrastructures become software-driven. Smart virtual workplace provides end to end desktop virtualization allowing employees to access applications, data safely over any network from the device of any choice. New trends show that business will increasingly turn to hybrid cloud solutions to enable scalable business processes. Hybrid clouds can quickly scale to a company's needs and services can be paid for as needed. They combine the best of two worlds, offering true benefits to intelligent enterprises aiming to stay ahead in their markets.

\subsection{E-Collaboration}

E-collaboration is the standard for business communication today, nearly eliminating the need to meet face to face. While knowledge sharing increases, formal and informal groups become e- collaborative communities to reach organizational goals. Intelligent enterprises continue to integrate these into their business processes and reinvent their customer engagement models.

In the intelligent enterprise ICT tools allow disparate teams to work together in real-time, enabling multiple individuals to interact as efficiently and effectively with coworkers, clients, and suppliers.

\subsection{Business flexibility}

The intelligent enterprise can be called as the designer of changes where the business flexibility is crucial. ICT solutions are very helpful in this case. They must now be highly flexible and resilient in order to seamlessly communicate and interoperate with disparate technologies and systems. The IaaS model becomes very useful. It makes it easier the internetworking and deploying servers and endpoints from multiple sources.

\subsection{Scalability and customization}

Intelligent enterprises align their IT infrastructure capabilities with business requirements. Modularity of systems, applications allow companies to have only what is needed at present, trimming up-front costs and leaving open the possibility of expanding or incorporating new technologies in the future. With the increase of consolidation, intensive virtualization, the traditional data center will transform to the 'hyperscale' data center. It requires a fundamentally different approach than that taken with typical enterprise IT systems. Rather than building 'monolithic' platforms, distributed architecture design is implemented around distributed processing frameworks. That requires software and ICT tools that automate node deployment, recover from failure (rerouting of workloads), and other management and monitoring tools.

\subsection{Business continuity}

It is obvious that intelligent companies need to have 24 hours a day access to their data. Data digitalization and rapidity of their processing require more accurate, reliable 
and sophisticated ICT tools converting all data into intelligence for better business outcomes. On the other hand, managers need them to be not complicated in their use. Moreover, for a high level of operational uptime, infrastructure components must be fault tolerant with the ability to recover from complex failures and data storage must be secure.

\subsection{Converting data into business intelligence}

Advanced ICT solutions enable extracting from huge amounts of data collected from the real cyberspace. Intelligent enterprises are able to manage Big Data to drive better business processes, product development, and customer service. The important is the fact that they enable to use effectively unstructured data captured from different systems, mobile devices, social media, log files, emails to perform real-time context analytics to understand received information, its content to make right decisions in the right time.

Therefore, intelligent enterprises are not only the users of advanced tools based on ICT technologies to optimize business practices, drive workforce engagement and create a competitive edge, but they are also able to leverage and to create value from the date and information generating by ICT solutions.

\section{CONCLUSIONS}

The discussion about intelligent enterprise is at the beginning stage. There are more theoretical disputes then surveys in this case. There are no in depth research devoted business models of these organizations or effectiveness, strategy or management in this organizations, especially with use of ICT solutions.

In the paper, there were presented two surveys that can be the good start for the future research about intelligent enterprises. Poland is at the stage of an intensive investing in the research and development, therefore Polish companies are still learning how to create the intelligence and how to be intelligent organizations. This is especially a challenge for companies from the SMEs sector.

The research conducted by MIT Sloan Management Review and the IBM Institute for Business Value show that for the intelligent enterprise, the new reality is this: personal experience and insight are no longer sufficient. New analytics capabilities are needed to make better decisions.

The above premises encourage the author to continue the scientific discussion about intelligent enterprise with a special attention to ICT solutions. The advanced research will be continued.

\section{REFERENCES}

[1] "The Intelligent Enterprise: A New Paradigm, Academy of Management Executive, 6(4), 1992

[2] Y. H. Ming, and D. X. Feng: "Research on the Intelligent Enterprise Based on Intelligent Behavior", Proceedings of the 7th International Conference on Innovation and Management, Vols. I and II, 2010, pp. 2094-2099.

[3] M. S. Hopkins, S. Lavalle, and F. Balboni: "10 Insights: A First Look at The New Intelligent Enterprise Survey", Mit Sloan Manage Rev, 2010, $52,(1)$, pp. 22.

[4] N. Kruschwitz, and R. Shockley: "First Look: The Second Annual New Intelligent Enterprise Survey", Mit Sloan Manage Rev, 2011, 52, (4), pp. 87-89.

[5] B. Dayyani: "The Intelligent Enterprise: Knowledge-Driven Category Management", Proceedings of the 7th International Conference on Intellectual Capital, Knowledge Management and Organisational Learning, 2010, pp. 138-145.

[6] J. B. Quinn: "The intelligent enterprise a new paradigm", Acad Manage Exec, 2005, 19, (4), pp. 109-121.

[7] E. Stubbs: 'The Intelligent Enterprise', Wiley Sas Bus Ser, 2014, pp. 79-93

[8] "The intelligent enterprise and the changing role of computer information systems in strategic planning", Information Resources Management Journal, 1991, 4, (1), pp. 21-29.

[9] B. Tan, X. W. Cao, and D. Ahpak: "Achieving Competitive Advantage through Building an Intelligent Organization with Technological Innovation: The Case Of A Chinese Enterprise", Proceedings of 2010 International Conference on Innovation, Management and Service, 2010, pp. 24-29.

[10] E. Szczerbicki: "Intelligent enterprise management", Cybernet Syst, 2001, 32, (7), pp. 697-699.

[11] S. G. Wang., R. Liu, and X. T. Liu: "An enterprise intelligent system development and solution framework", Icemi 2007: Proceedings of 2007 8th International Conference on Electronic Measurement \& Instruments, Vol Iv, 2007, pp. 115-118.

[12] J. N. Gupta, and S.K. Sharma: "Creating knowledge based organizations", Igi Global, 2004.

[13] G. H. Stonehouse, and J. D. Pemberton: "Learning and knowledge management in the intelligent organisation", Participation and Empowerment: An International Journal, 1999, 7, (5), pp. 131-144.

[14] E. Szczerbicki, Z. Gomółka, "Management of Information in Complex Systems: Perspectives for New Millenium", Intelligent Processing and Manufacturing of Materials, IPMM '99. Proceedings of the Second International Conference on Vol. 2,1999, DOI: 10.1109/IPMM.1999.791491.

[15] M. J. Thannhuber: "The Intelligent Enterprise", Springer, 2005.

[16] U. Dayal, „Managing the intelligent enterprise”, e-Commerce Technology, 2004. CEC 2004. Proceedings. IEEE International Conference on 2004, DOI: 10.1109/ICECT.2004.1319711.

[17] "Business analytics and optimization for the intelligent enterprise", IBM Institute for Business Value, IBM Global Business Services Executive Report, USA 2009.

[18] P. Kordel, J. Kornecki, K. Pylak, J. Wiktorowicz, A. Kowalczyk, K. Krawczyk, "Inteligentne organizacje - zarządzanie wiedzą i kompetencjami pracowników", Warszawa 2010.

[19] S. LaValle, E. Hopkins, R. Lesser, M.S. Shockley, N. Kruschwitz, "Big Data, Analytics and the Path From Insights to Value, Research Feature, December, 2010. 